ISSN 2179-6750

\title{
A judicialização dos medicamentos e os efeitos nas despesas de saúde no Brasil
}

\author{
Amanda Natasha Menardo CLARO(1) \\ Jaqueline Vilela BULGARELI ${ }^{(1)}$ \\ ${ }^{(1)}$ Faculdade de Saúde Pública, Universidade de São Paulo - USP, São Paulo, SP, Brasil.
}

Recebido: 28 jan 2019 Aceito: 10 fev 2019

Autor de correspondência: anmclaro@gmail.com

Conflito de interesses: Os autores declaram não haver nenhum interesse profissional ou pessoal que possa gerar conflito de interesses em relação a este manuscrito.

\section{Resumo}

A lei orgânica da saúde (Lei 8.080 /90) consolidou no Brasil a defesa por melhores condições da saúde e da vida, pautada num sistema de atendimento público com qualidade e universalidade. Enquanto a Organização Mundial da Saúde - OMS estabelece que cada país elabore sua própria lista de medicamentos essenciais para atender as necessidades da população, no Brasil, a Comissão Nacional de Incorporação de Tecnologias - CONITEC, no Sistema Único Saúde, é responsável por assessorar o Ministério da Saúde - MS nas atribuições relativas à incorporação, exclusão ou alteração de tecnologias em saúde pelo SUS, bem como na constituição ou alteração do Protocolo Clínico e Diretrizes Terapêuticas - PCDT e atualização da Relação Nacional de Medicamentos Essenciais RENAME. A CONITEC realiza análises baseadas em estudos de evidências científicas e impactos orçamentários para determinação dos procedimentos e medicamentos contemplados nas diretrizes terapêuticas. No entanto, muitas vezes os medicamentos prescritos pelos médicos não contemplam as listas do SUS, além de apresentarem um custo monetário alto, tornando-se inacessível para a população. Diante deste cenário, com a demanda por saúde infinita e recursos finitos, a judicialização da medicina, no tocante aos pedidos de medicamentos, vem impondo certa iniquidade aos usuários, para o atendimento de sua demanda. Esta reação influencia as políticas públicas do SUS, pois obriga que suas reservas de custos programados, sejam desviadas para o cumprimento das ações judiciais, resultando no protelamento ou cancelamento de outros recursos previstos. Existem muitos pontos a serem discutidos neste contexto, como por exemplo, é de se questionar se o tratamento com o medicamento de alto custo seria a única opção para aquele paciente. As situações em que a política pública não se faz presente da forma esperada, a judicialização da medicina pode representar um caminho legítimo de reivindicação de direitos dos usuários. Até que ponto a precificação do medicamento pelas indústrias está correta no campo da ética e acesso ao tratamento da população? No que tange a CONITEC, os critérios estabelecidos para incorporação de uma nova tecnologia são cumpridos à risca ou existe algum viés de interesse político nestas análises? O prazo estabelecido para incorporação e disponibilidade do medicamento para a população e cumprido, conforme previsão da legislação? Investimentos acentuados em prevenção de doenças na atenção primária mitigariam a medicalização da saúde? O financiamento à saúde no Brasil é adequado, ou seja, 
gastar maiores frações do PIB com financiamento do sistema de saúde significa melhores condições de saúde para a população? Comparado com outros Países que investem uma parcela maior em saúde, é possível afirmar que existe equidade de acesso a saúde? Os resultados destas ações judiciais geram efeitos importantes na economia dos estados e consequências à população em geral. $\mathrm{A}$ questão a ser explanada e debatida é, qual o tamanho desse impacto? E ainda, será que existem medidas que proponham acesso aos tratamentos medicamentosos adequados sem impactar aos cofres públicos? Objetivo: $O$ objetivo do estudo é identificar as despesas em saúde direcionadas para atender demandas judiciais de medicamentos. Método: Foi realizada uma revisão integrativa que emerge como uma metodologia que proporciona a síntese do conhecimento e a incorporação da aplicabilidade de resultados de estudos significativos na prática. O método escolhido constitui basicamente um instrumento da Prática Baseada em Evidências - PBE. A PBE, cuja origem atrelouse ao trabalho do epidemiologista Archibald Cochrane, caracteriza-se por uma abordagem voltada ao cuidado clínico e ao ensino fundamentado no conhecimento e na qualidade da evidência. Envolve, pois, a definição do problema clínico, a identificação das informações necessárias, a condução da busca de estudos na literatura e sua avaliação crítica, a identificação da aplicabilidade dos dados oriundos das publicações e a determinação de sua utilização para o paciente. Esta revisão integrativa tem como objetivo identificar as despesas em saúde direcionadas para atender demandas judiciais de medicamentos. Considerações finais: Inicialmente foi realizada a técnica do funil, para tal análise selecionamos quatro bases de dados: LILACS, MEDLINE, SciELO e PubMed. Os operadores booleanos utilizados foram o $A N D$ e $O R$ e utilizamos nove combinações de descritores: (tw:(Indicadores de Impacto Social )) $A N D$ (tw:(MEDICAMENTOS)), (tw:(JUDICIALIZAÇÃO DA SAUDE)) AND (tw:(MEDICAMENTOS)), (tw:(JUDICIALIZAÇÃO DA SAUDE)) AND (tw:(MEDICAMENTOS)) AND (tw:(VIGILANCIA SANITARIA)), (tw:(Contas Nacionais de Saúde )) OR (tw:(Custeio )) OR (tw:(despesas)) OR (tw:(gastos)) AND (tw:(medicamentos)) $A N D$ (tw:(judicialização)), Health Care Costs[MeSH] $A N D$ judicialAll Fields], ((("Health Care Costs"[MeSH]) AND judicial)) AND DRUG, (MEDICATION) AND Health judicialization, (DRUG) AND Health judicialization e (JUDICIALIZATION) AND MEDICINES. No total, 88 artigos foram identificados na estratégia de busca traçada. Critérios de inclusão: todos os textos disponíveis para leitura nas bases de dados selecionados que tratassem do assunto judicialização dos medicamentos no Brasil e no mundo, independente da classificação do medicamento ou ano de publicação do artigo. Critérios de exclusão: foram excluídos os textos que não abordassem o tema judicialização de medicamentos no Brasil e em outros países, que não estivessem disponíveis como texto completo e os artigos repetidos.

Descritores: Indicadores de Impacto Social; Judicialização da Saúde; Vigilância Sanitária. 